\title{
The effect of the quality of work life (QWL) on career integration: A Survey study in Al-Hadba University College
}

Journal of

TANMIYAT ALRAFIDAIN

\section{(TANRA)}

A scientific, quarterly, international, open access, and peer-reviewed journal

Vol. 39, No. 128

Dec., 2020

(C) University of Mosul | College of Administration and Economics, Mosul, Iraq.

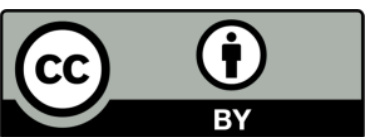

TANRA retain the copyright of published articles, which is released under a "Creative Commons Attribution License for CC-BY-4.0" enabling the unrestricted use, distribution, and reproduction of an article in any medium, provided that the original work is properly cited.

Citation: Sultan, Mohammed M. and Al- Ta'e, Adel M. Abdullah (2020)."The effect of the quality of work life (QWL) on career integration: A Survey study in Al-Hadba University College". TANMIYAT AL-RAFIDAIN, 39 (128), 9-30, https://doi.org/ 10.33899/tanra.2020.167367

P-ISSN: 1609-591X e-ISSN: 2664-276X tanmiyat.mosuljournals.com

\author{
Mohammed M. Sultan'; Adel M. Abdullah Al- Ta' ${ }^{2}$ \\ 1\&2 College of Administration and Economics; University of Mosul \\ Corresponding author: Adel M. Abdullah Al- Ta'e, \\ adel_mohamed@uomosal.edu.iq
}

DOI: 10.33899/tanra.2020.167367

Article History: Received: 5/1/2020; Revised: 14/2/2020; Accepted: 14/2/2020; Published: $1 / 12$ /2020.

\begin{abstract}
The research aims to determine the extent of the impact of the quality of work life on the career integration of workers in the Hadba University College, where a comprehensive survey method was used for all of the research community, which consisted of (137) individuals from the Hadba University College, as an applied field for the current research, through A questionnaire prepared for this purpose. The research reached a basic result according to the presence of a statistically significant relationship between the quality of work life and job integration for workers in the researched college. The research also showed that the dimensions of the quality of work life are available in the researched college with an acceptable and medium degree, and that the degree of integration of workers in their work was good.

In the light of the conclusions reached by the research, a set of recommendations was presented that are consistent with these conclusions, the most important of which is the need to pay attention to raising the quality of work life in the researched college. In addition to inviting researchers to submit more research related to the current topic of research in different fields.
\end{abstract}

\section{Keywords}

Quality of Work Life, Career integration. 


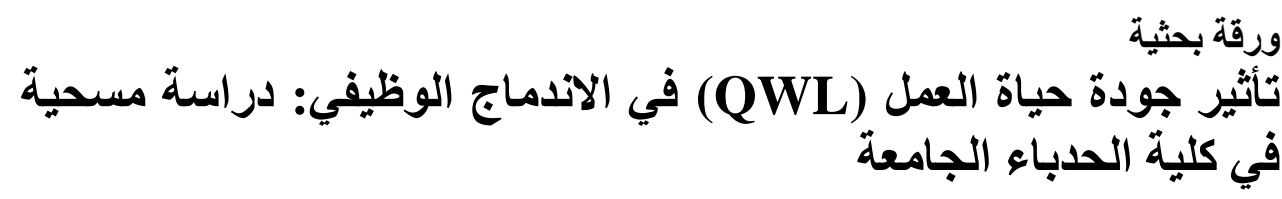

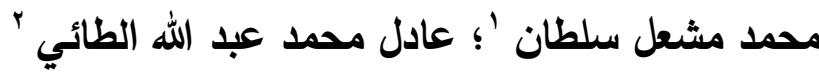

إ\& جامعة الموصل، كلية الإدارة والاقتصاد، قسم إدارة الاعمال

adel mohamed@uomosul.edu.iq ، المؤلف المراسل: عادل محمد عبد الله DOI: 10.33899/tanra.2020.167367

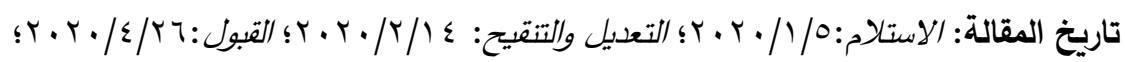

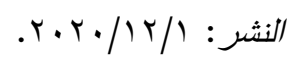

المستخلص

يهذف الجحث الى تحديد مدى تأثير جودة حياة العدل (QWL) على الاندماج الوظيفي للعاملين في كلية

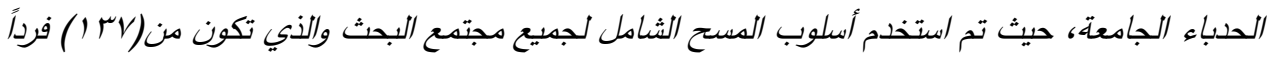

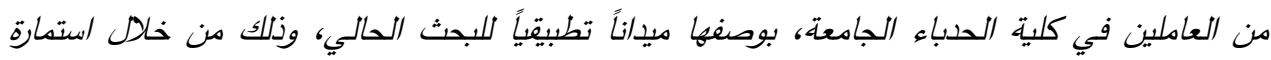

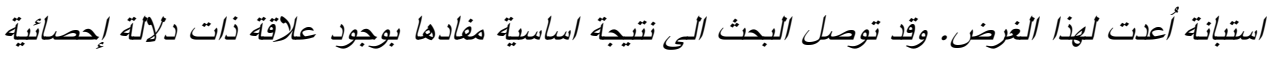

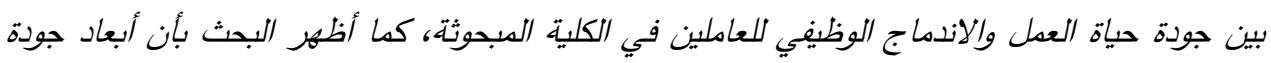

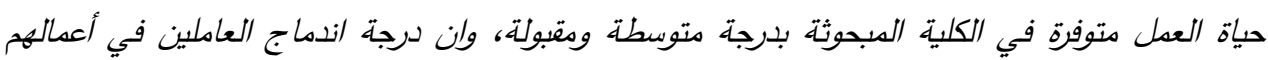
كانت جيدة.

وفي ضوء الاستنتاجات التي توصل اليها البحث، تم تقديم مجدوعة من التوصيات التي تنسجم مع هذه

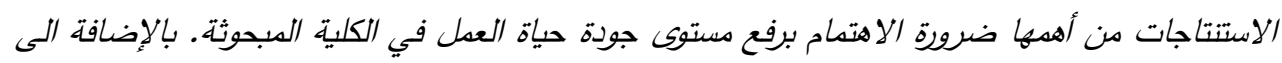
دعوة الباحثين الى تقديم المزيل من البحوث ذات الصلة ببوضوع البحث الحالي وفي ميادين مغايرة.

الكلمات المفتاحية جودة حياة العمل، الاندماج الوظيفي.

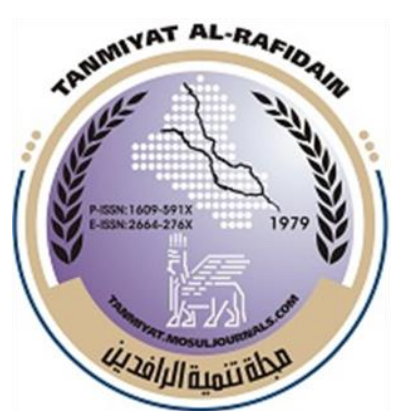

\section{همبالة}

\section{تنسميسة الرافدين}

(TANRA) دولية، مفتوحة الوصول، محكمة.

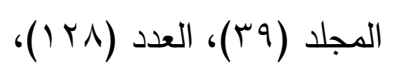

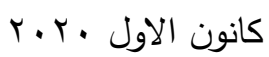

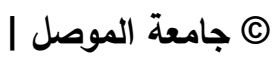
كلية الإدارة والاقتصاد، الموصل، العوصل العراق.

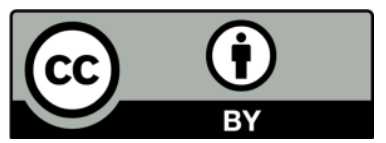

تحتفظ (TANRA) بحقوق الطبع والنشر للدقالات المنشورة، والتي يتم إصدارها بموجب ترخيص

\lrcorner (Creative Commons Attribution) (CC-BY-4.0)

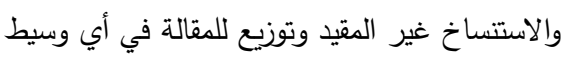
نقل، بشرط اقتباس العمل الأصلي بشكل صحيح.

الاقتباس: سلطان، محمد مشعل و الطائي

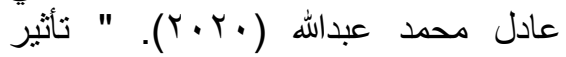
جودة حياة العمل (QWL) في الاندماج الوظيفي: دراسة مسحية في كلية الحدباء

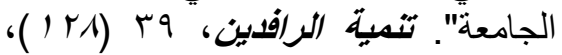
6.

https://doi.org/10.33899/tanra.20 20.167367

P-ISSN: 1609-591X

e-ISSN: 2664-276X

tanmiyat.mosuljournals.com 
يعد المورد البشري من أهم الموارد وأثثنها لعمل المنظمات سيما التعليمية منها، حيث يلعب دوراً

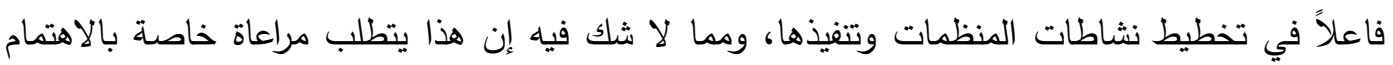

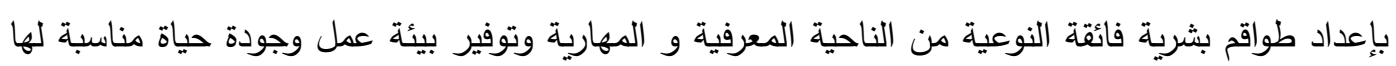

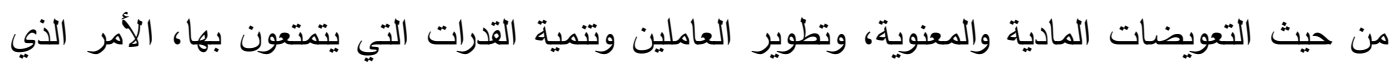
سينعكس بالإيجاب أو السلب نحو اندماجهم، ذلك الاندماج الذي يحصل بثلاثة أشكال هي: الاندماج

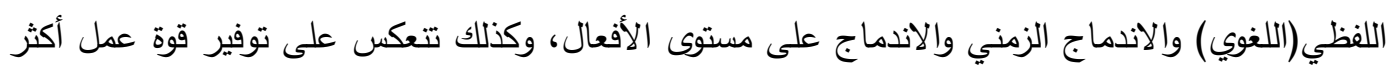
مرونة وولاء وبالتالي تحقيق أهداف المنظمة وتعظيم القدرة التتافسية لها.

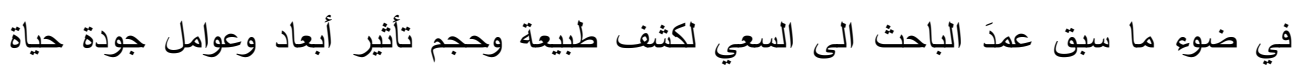
العمل في الاندماج الوظيفي لدى العاملين في كلية الحدباء الجامعة، والتي تسعى لتقديم الخدمات التعليمية والارتقاء بهذه الخدمات، مستخدمة المقررات العلمية لخدمة الآلاف من الدارسين فيها.

1- المنهجية

من أجل إيضاح معالم البحث نقدم الخطوط العريضة للمنهجية وفق الفقرات الآتية: 1- المشكلة اجن المن

يبحث البحث الحالي في الفجوة المعرفية الناتجة عن التفاوت بين متغيرات(أبعاد) جودة حياة العمل والاندماج الوظيفي للعاملين، وبالتالي يسهم البحث في توضيح الطريقة التي تمكن المنظمة من توفير

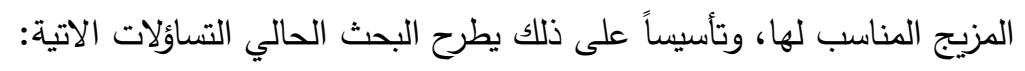

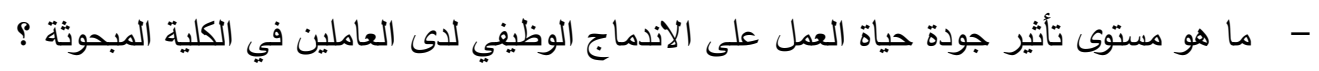

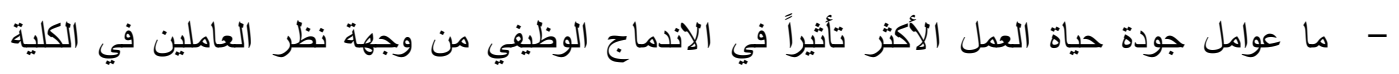

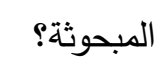

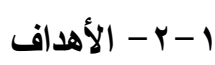

يهدف البحث الى تحقيق ما يأتي: ا. التعرف على أثر جودة حياة العمل في الاندماج الوظيفي لاى العاملين في الكلية المبحوثة. r. معرفة واقع جودة حياة العمل بعناصرها المختلفة لدى العاملين في الكلية المبحوثة. r. الاشارة الى جهود الباحثين الذين أسهموا في الكتابة عن متغيرات البحث. 1-r- الفرضيات ومخطط البحث يقدم البحث الحالي الفرضيات الاتية: لا يوجد أثر معنوي ذو دلالة إحصائية للتعويض المجزي في الاندماج الزمني في العمل عند مستوى لئل المعنوية 0.05 
H0:2 لا يوجد أثر معنوي ذو دلالة إحصائية للتعويض المجزي في الاندماج اللفظي في العمل عند مستوى

$$
\text { المعنوية } 0.05
$$

H0:3 لا يوجد أثر معنوي ذو دلالة إحصائية للتعويض المجزي في اندماج العاملين المرتبط بالأفعال عند

$$
\text { مستوى المعنوية } 0.05
$$

H0:4 لا يوجد أثر معنوي ذو دلالة إحصائية لتطوير القدرات في الاندماج الزمني في العمل عند مستوى

$$
\text { المعنوية } 0.05
$$

H0:5 لا يوجد أثر معنوي ذو دلالة إحصائية لتطوير القدرات في الاندماج اللفظي في العمل عند مستوى

$$
\text { المعنوية } 0.05
$$

لا يوجد أثر معنوي ذو دلالة إحصائية لتطوير القدرات في اندماج العاملين المرتبط بالأفعال عند

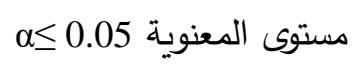

لا يوجد أثر معنوي ذو دلالة إحصائية لدستور المنظمة في الاندماج الزمني في العمل عند مستوى

$$
\text { المعنوية } 0.05
$$

H0:8 لا يوجد أثر معنوي ذو دلالة إحصائية للدستور المنظمة في الاندماج اللفظي في العمل عند مستوى

$$
\text { المعنوية } 0.05
$$

لا يوجد أثر معنوي ذو دلالة إحصائية لدستور المنظمة في اندماج العاملين المرتبط بالأفعال عند

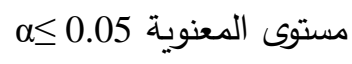

H0:10 لا يوجد أثر معنوي ذو دلالة إحصائية لظروف العمل في الاندماج الزمني في العمل عند مستوى

$$
\text { المعنوية } 0.05
$$

H0:11 لا يوجد أثر معنوي ذو دلالة إحصائية لظروف العمل في الاندماج اللفظي عند مستوى المعنوية $\alpha \leq 0.05$

لا يوجد أثر معنوي ذو دلالة لظروف العمل في اندماج العاملين المقترن بالأفعال عند مستوى

$$
\text { المعنوية } 0.05
$$




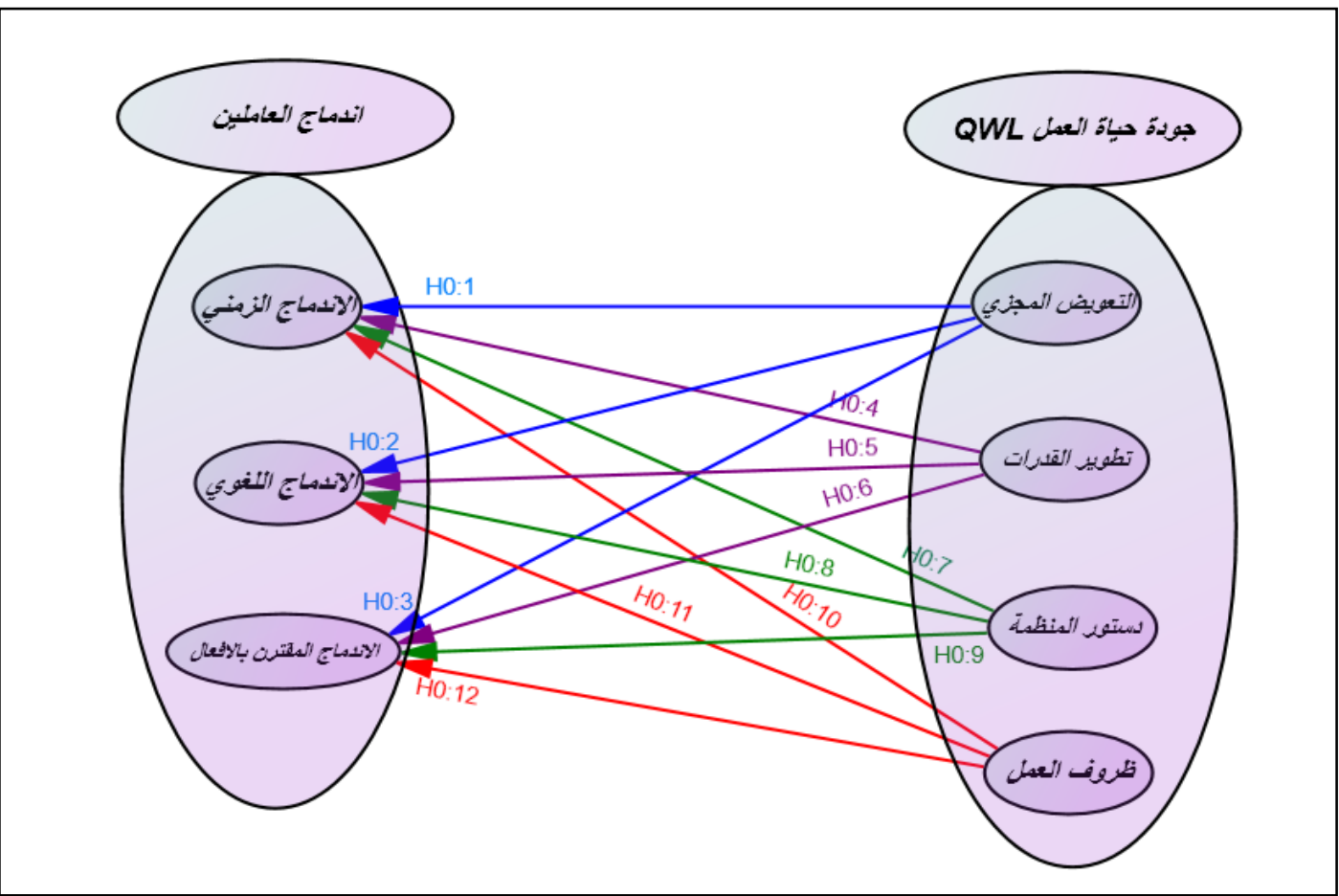

المصدر : إعداد الباحثين

$$
\text { - - الأهمية }
$$

يستمد البحث الحالي أهميته من كونه يعالج موضوع حيوي ومهم يمثل قوة انتماء وارتباط العامل بوظيفته لدرجة تجعله يبذل أقصى ما لديه لضمان سيرورة العمل، والذي ينعكس على أدائه وعلى جودة الخدمة التعليمية. كما تكمن اهمية البحث في زيادة الاهتمام بالموارد البشرية في الكلية المبحوثة بغية رفع مستوى اندماجهم في العمل، من خلال توفير جودة حياة مناسبة يشعر عن طريقها العاملين بالراحة والاطمئنان. 1-0 - وصف خصائص أفراد عينة البحث

وزعَ الباحث VV IT استمارة استبيان وهم مجموع العاملين في كلية الحدباء الجامعة، كونها الحالة المدروسة في البحث الحالي، حيث تتوعت المستويات الإدارية لكل موظف فيها، مع ملاحظة اعتماد

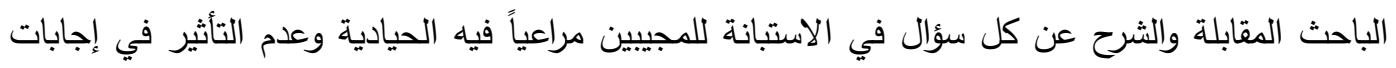

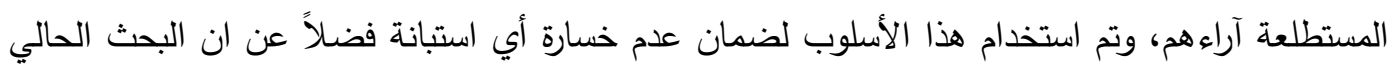

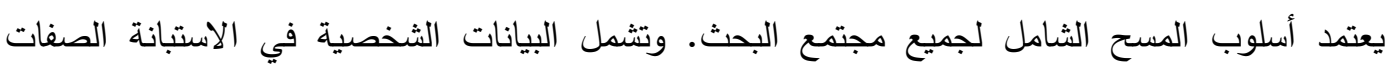


الديموغرافية من حيث (الجنس، العمر، الحالة الاجتماعية، التحصيل الدراسي، مدة الخدمة، والمستوى الإداري).

يوضح الجدول (1) ان ما نسبته 38.7\% من عينة البحث هم من فئة ما فوق الثلاثين سنة دلالة على توازن الهرم العمري في العينة المبحوثة، ولا تعاني عينة البحث من الترهل في اعمار المجيبين، وبالتالي يؤشر على امتلالك كلية الحدباء لنسبة عالية من الفئات العمرية المتميزة والطاقات الشبابية ذات القدرة على إنجاز المهام.

\begin{tabular}{|c|c|c|}
\hline الفئات & التكرارات & النسبة المئوية \\
\hline $18-30$ & 38 & 27.7 \\
\hline $31-40$ & 53 & 38.7 \\
\hline $41-50$ & 13 & 9.5 \\
\hline -51فاكثر & 33 & 24.1 \\
\hline Total & 137 & 100.0 \\
\hline
\end{tabular}

المصدر: اعداد الباحثين وفق مخرجات نظام SPSS

وفيما يرتبط بالجنس نلاحظ من الجدول (r) ان 80\% من الميبين من الذكور مقابل (20\%) للإناث وهذا دلالة على ان المنظمة المبحوثة تفضل في التعيين الذكور على الإناث.

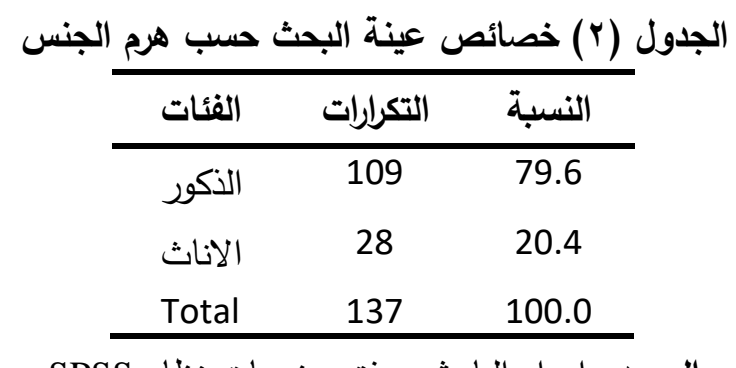

SPSS المصدر اعداد الباحثين وفق مخرجات نظام

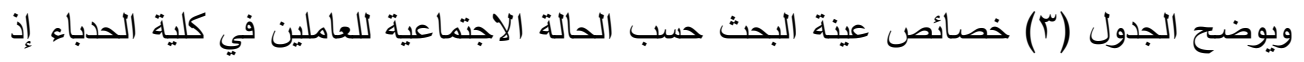
أشرت نتائج الجدول إن غالبية الأفراد المبحوثين هم من فئة المتزوجين والتي بلغت (75.9\%)، وأما فئة

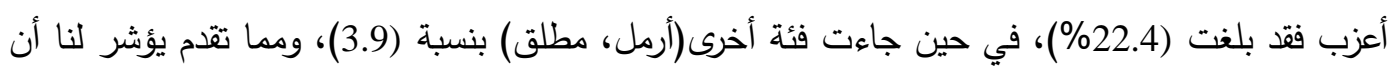
غالبية الأفراد المبحوثين لديهم التزامات عائلية. 


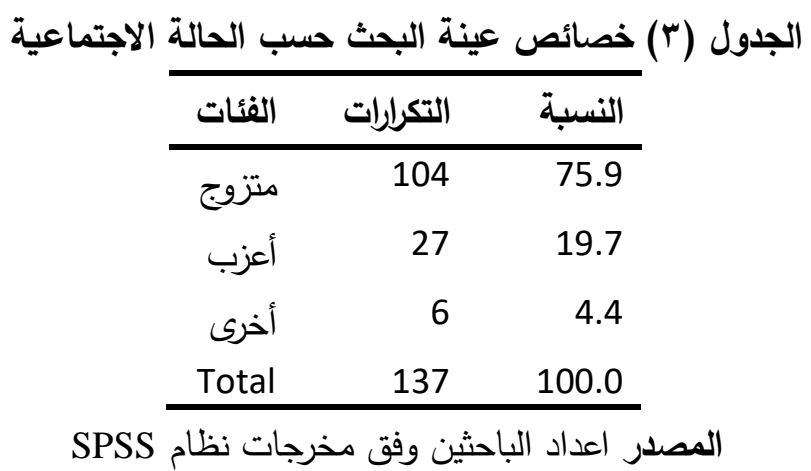

من جهة أخرى يوضح الجدول (ء) ارتفاع نسبة الأفراد المبحوثين الذين يحملون شهادة الماجستير إذ شكلت (32\%) من اجمالي افراد العينة، ثم تليها نسبة الأفراد الذين يحملون شهادة البكالوريوس إذ بغلت (26\%) من مجموع أفراد العينة، ثم تليها نسبة الأفراد الذين يحملون شهادة الدكتوراه وشكلت (21\%)، وفي ضوء هذه النسب نلاحظ ان النسبة الكلية للأفراد المبحوثين الذين يحملون الشهادات العليا بلغت (55\%) وهذا مؤشر جيد، يدل على ارتفاع مستوى الوعي الثقافي لاى المستجيبين.

\begin{tabular}{|c|c|c|}
\hline الفئات & التكرارات & النسب \\
\hline أقل من & 25 & 18.2 \\
\hline \multicolumn{3}{|l|}{ بكالوريوس } \\
\hline بكالوريوس & 36 & 26.3 \\
\hline دبلوم عالي & 1 & 0.7 \\
\hline ماجستير & 45 & 32.8 \\
\hline دكتوراه & 30 & 21.9 \\
\hline Total & 137 & 100.0 \\
\hline
\end{tabular}

المصدر اعداد الباحثين وفق مخرجات نظام SPSS

في حين أفرزت معطيات الجدول(0) أن (51.8\%) من الأفراد المبحوثين بلغت سنوات خدمتهح الوظيفية ب(أقل من 5 سنوات) وهي الفئة الأكثر من بين الفئات الأخرى، وبالمقابل فإن(21.2\%) منهم تراوحت خدمتهم ما بين (6-10) سنة، في حين جاءت الفئات (11-15) (16-20) (21سنة فأكثر) التي مثلت نسبة (10.2\%) (8.0\%) (8.8\%) على التوالي، مما يوفر لنا منطلقاً للقول بأن الفئات الأقل خدمة 
في المنظمة المبحوثة هم الأكثر عدداً، ومرد ذلك الى طبيعة الظروف والمتغيرات، فضلاً عن الإجراءات

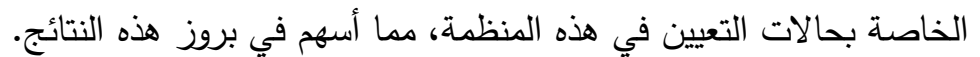

\begin{tabular}{|c|c|c|}
\hline الفئات & التكرارات & النسبة \\
\hline اقل من 5 سنوات & 71 & 51.8 \\
\hline 6- 10 & 29 & 21.2 \\
\hline $11-15$ & 14 & 10.2 \\
\hline $16-20$ & 11 & 8.0 \\
\hline 21فأكثر & 12 & 8.8 \\
\hline Total & 137 & 100 \\
\hline
\end{tabular}

ويوضح الجدول (؟) خصائص عينة البحث حسب هرم المستوى الإداري في الكلية المبحوثة إذ إذبين وضح هذا الجدول ان 52.6\% من المجيبين هم في المستوى الإداري الوسط وهي النسبة الأكثر من بين

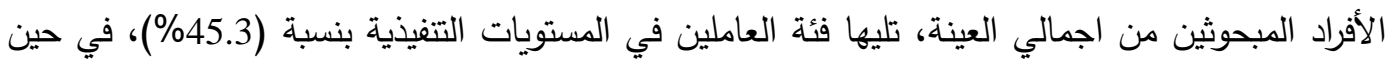

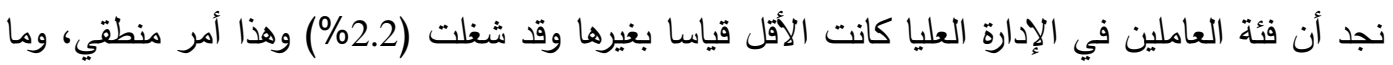

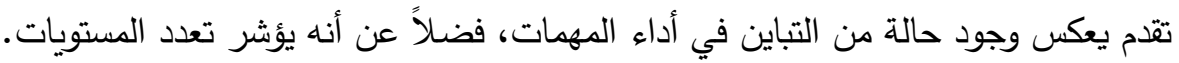
الجدول (†) خصائص عينة البحث حسب هرم المستوى الإداري

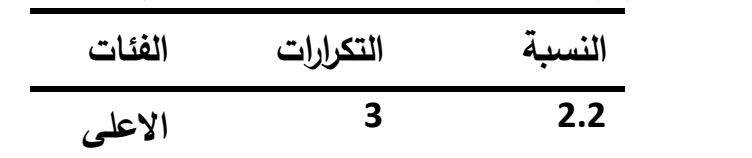

\begin{tabular}{rrr} 
الاوسط & 72 & 52.6 \\
Total & 62 & 45.3 \\
\hline
\end{tabular}

المصدر اعداد الباحثين وفق مخرجات نظام SPSS

$$
\text { 1- - أساليب جمع البيانات وتحليلها. }
$$

- أساليب جمع البيانات: حيث اعتمد الباحثان أكثر من أسلوب لجمع البيانات التي تعد الأساس في إبراز

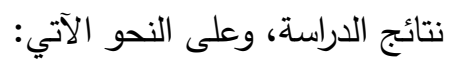

أ-الجانب النظري: اعتمد الباحثان في تغطية الجانب النظري على المصادر العربية والأجنبية ذات العلاقة بالدراسة الحالية، فضلاً عن الإفادة من شبكة الانترنيت لجمع البحوث والدراسات ذات البهات

$$
\text { الاختصاص بموضوع البحث الحالي. }
$$

ب- الجانب العملي: اعتمد الباحثان في توفير البيانات للجانب العملي على الوسائل الآتية: 
1- تحليل المحتوى والذي يشمل سجلات كلية الحدباء الجامعة والتي نحصل عليها من أقسام وشعب الكلية قدر ارتباطها بموضوع البحث، بالإضافة الى المقابلات الشخصية التي جرت مع العاملين.

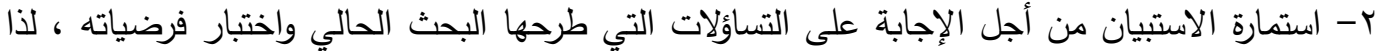
تم توزيع الاستبانة بعد عرضها على السادة المحكمين من أجل تقويمها، وبما يتطابق مع موضوع الإنى البحث وأهدافه، حيث تم توزيعها على العاملين في الإدارات والاقسام والثعب في الإدارة العليا والوسطى والتنفيذية في الكلية المبحوثة. وتم إعداد الاستبانة وفق هيكلية مكونة من جزئيين: الأول الادلي يثمل البيانات الديموغرافية من حيث (الجنس، العمر، الحالة الاجتماعية، التحصيل العلمي، مدة

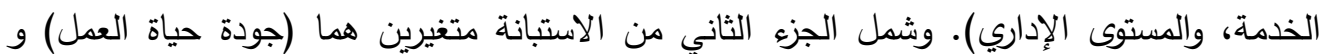

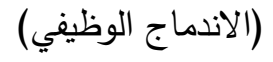

- - - أساليب تحليل البيانات

من أجل تحقيق أهداف البحث واختبار فرضياته تم استخدام برنامج (AMOS) وهو أداة إحصائية

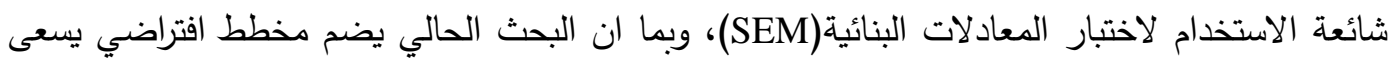
لاختباره ويضم في مكنوناته متغيرات رئيسية وأبعاد فرعية فان هذا البرنامج يعتبر أفضل وسيلة لاختبار صحة هذه العلاقات بين متغيرات المخطط، وذلك لما يضم هذا البرنامج من مؤشرات منها التحليل العاملي التوكيدي الذي يستخدم للتأكد من العلاقة بين المتغيرات التوضيحية والمستجيبة، كما يقدم برنامج AMOS

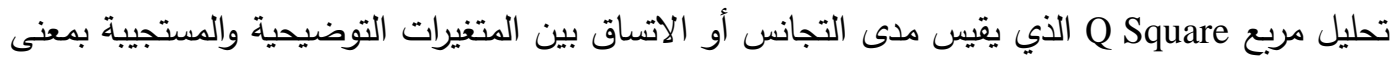
اخر (مدى انسجام جودة حياة العمل مع الاندماج الوظيفي للعاملين). كذلك يقدم برنامج AMOS مؤشرات

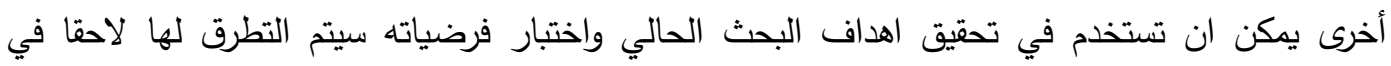

$$
\text { الجانب العملي من البحث. }
$$

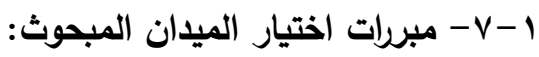

يسهم الاختيار الملائم والمناسب لمجتمع البحث وبشكل كبير في صحة النتائج واختبار الفرضيات، لذا تم اختيار كلية الحدباء الجامعة كميدان للبحث الحالي وذلك للمبررات الآتية: 1. تضم المؤسسات التعليمية مجموعة من النخب الأكاديمية والعلمية التي تعد إحدى ثروات التهات

$$
\text { المجتمعات وبالتالي يتطلب المحافظة على هذه الثروات. }
$$

r. أهمية الدور الاستراتيجي الذي تلعبه المنظمة المبحوثة في البناء الفكري والمعرفي والاجتماعي لأبتاتي

$$
\text { والثقافي لذا يتطلب الاهتمام والرعاية بمواردها البشرية. }
$$

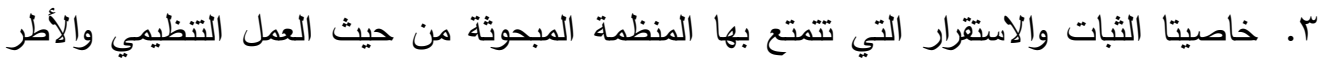

$$
\text { الادارية. }
$$

ع. حاجة المؤسسات التعليمية في البيئة العراقية الى دراسات ميدانية في هذا المجال. 


$$
\begin{aligned}
& \text { 1-1- حدود البحث }
\end{aligned}
$$

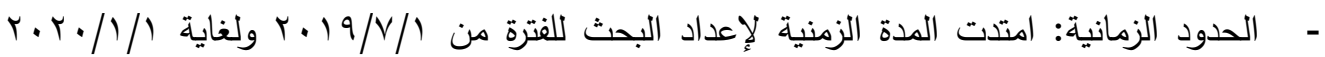

$$
\begin{aligned}
& \text { مدة اكمال البحث. } \\
& \text { - الحدود المكانية: تم البحث في كلية الحدباء الجامعة، إذ شمل اقسام الكلية جميعاً. } \\
& \text { - - الحدود البشرية: شملت عينة البحث الحالي جميع العاملين في الإدارات العليا والوسطى والتنفيذية، } \\
& \text { قدر تعلق الوظائف المختارة بمتغيرات البحث الحالي من جودة حياة العمل والاندماج الوظيفي. } \\
& \text { الاراسات السابقة } \\
& \text { :(Daud, 2012) - دراسة }
\end{aligned}
$$

"The influence of Quality of work life on organizational commitment: A study on Academic staff in public Institution of Higher learning in Malaysia."

"تأثير جودة حياة العمل على الالتزام التتظيمي: دراسة على الكادر الأكاديمي في المؤسسة العامة

$$
\text { للتعليم العالي في ماليزيا." }
$$

هدفت هذه الدراسة الى التعرف على العلاقة بين جودة حياة العمل وبين الالتزام التتظيمي لدى أعضاء هيئة التدريس في واحدة من أكثر المؤسسات الرائدة للتعليم العالي في ماليزيا. وقد تم استخدام المنهج الوصفي التحليلي في الدراسة، حيث اعتمد الباحث على الاستبانة كأداة رئيسية لجمع البيانات من فئن مجتمع الدراسة والمتمثل بالهيئة التدريسية في المؤسسة العامة للتعليم العالي، من خلال توزيع( • . ب)استبانة على الكادر التدريسي في كليات مختارة. حيث توصلت الدراسة الى عدة نتائج أهمها ان مستوى جودة حياة

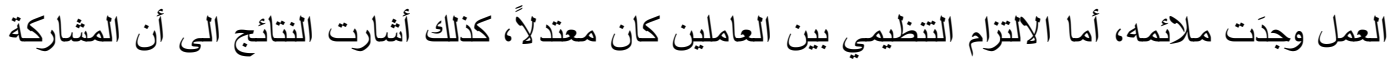
في صنع القرارات هي من أكثر العوامل الهامة والمؤثرة على الالتزام التنظيمي يليها النمو والتطوير .

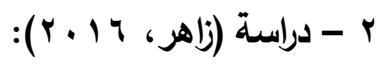

"أثر جودة حياة العمل في الالتزام التنظيمي: دراسة ميدانية على مركز خدمة المواطن(النافذة الواحدة)

(Zahir, 2016)

"The Impact of Quality of Work Life on Organizational Commitment: "A field study on the Citizen Service Center in Damascus Governorate.

هدفت هذه الدراسة الى معرفة مدى توافر أبعاد جودة حياة العمل في مركز خدمة المواطن في

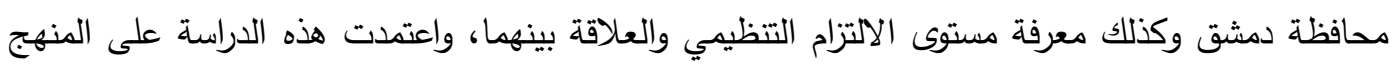

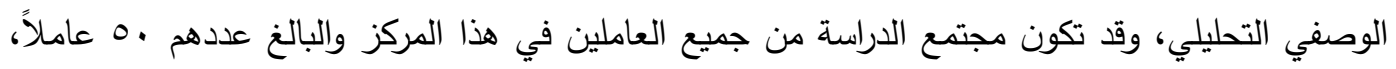


واستخدمت الاستبانة كأداة في جمع البيانات. و توصلت الدراسة الى عدد من النتائج أهمها وجود علاقة إيجابية ما بين جودة حياة العمل والالتزام التتظيمي، وكذلك وجود أثر لظروف بيئة العمل على الالتزام

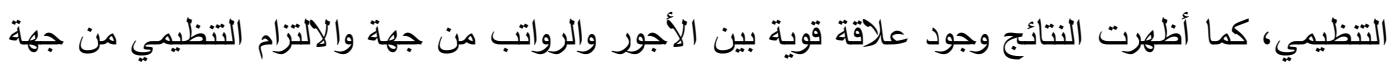

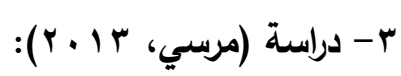

"أثر إدارة المواهب في اندماج العاملين من خلال التوازن بين العمل والأسرة كمتغير وسيط: دراسة

(Morsi, 2013)

ميدانية على مستثفيات جامعة الزقازيق" النماج المامين من

The Impact of Talent Management on the Integration of Employees through the Balance between Work and Family as a Mediating Variable, "A Field Study on Zagazig University Hospitals"

هدفت هذه الدراسة إلى قياس أثر إدارة المواهب على اندماج العاملين بثقيه الوظيفي والتتظيمي

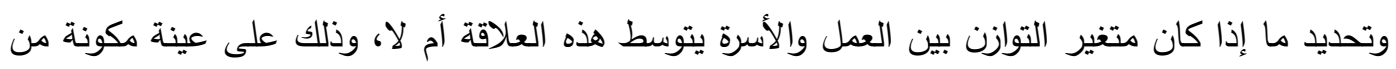

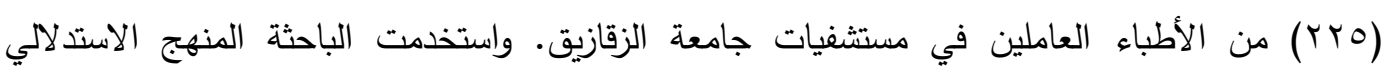

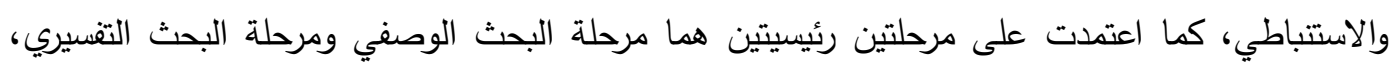

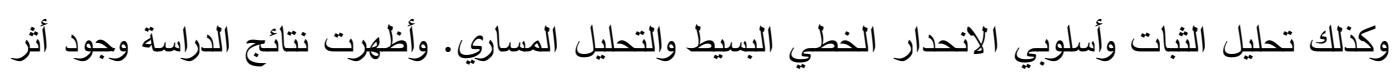
لإدارة المواهب في كل من الاندماج الوظيفي والتتظيمي للأطباء العاملين في المستثفيات المبحوثة، كما

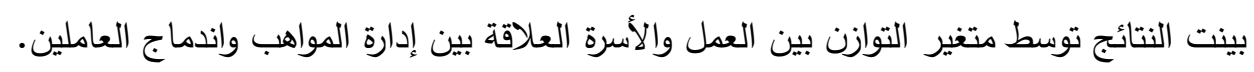

( 1 (Kasaya,2018)

Effect of employee involvement on job performance in the medical research "industry in Kenya "أثر إدماج الموظفين على الأداء الوظيفي في قطاع البحوث الطبية في كينيا"

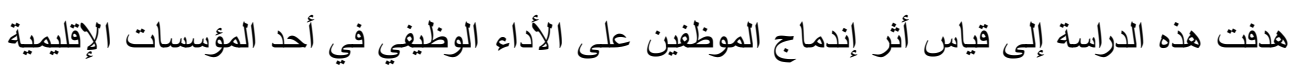

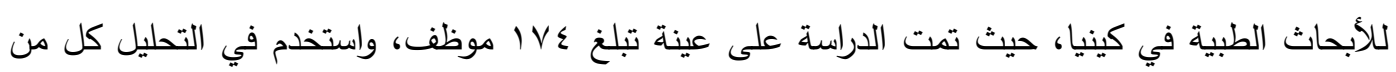
الإحصاء الوصفي والاستدلالي. وأظهرت نتائج الدراسة على أن تمكين الموظفين من المشاركة في الأمور

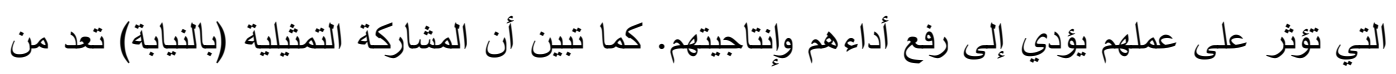

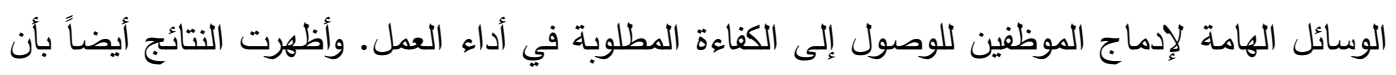
الموظفين في المؤسسة يتم إخبارهم بشكل دائم بأي جديد فيما يتعلق بالتوجه المستقبلي للمنظمة. r- (الجانب النظري 
عرف (Easton and vinlaar, 2018, 9) جودة حياة العمل بكونها مجموعة الأنشطة التي تمارسها المنظمات بغية تتمية وتطوير الحياة اثناء العمل بما ينعكس إيجابياً على تحسين أداء الفرد وزيادة انتاجية

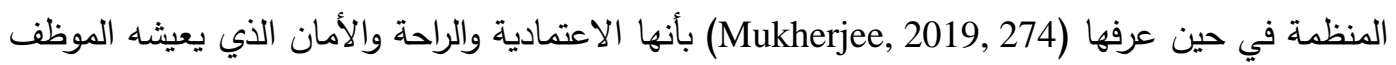

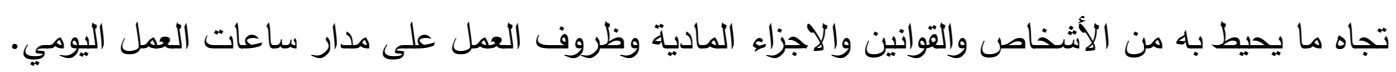

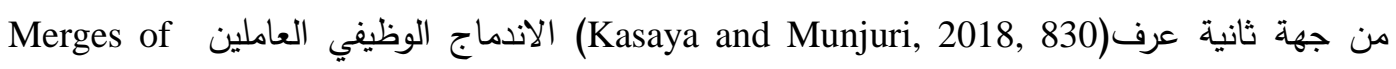
بكونه نسبة تركيز الموظف في العمل وبذله الوقت والجهد على نحو يتناسب والمعايير

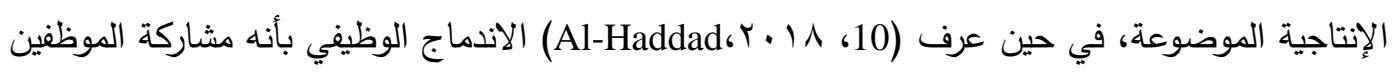

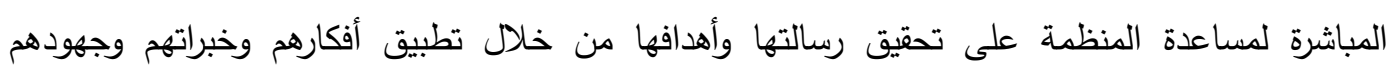

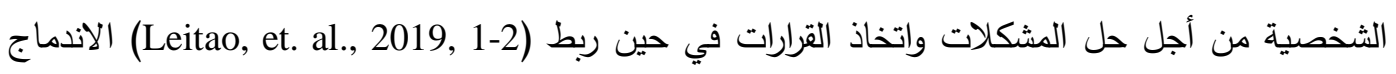
بالعمل والإنتاجية فعرفها بأنها قدرة وطاقة الموظف التي يوظفها في ممارسة التهارت عمله وزيادة مستوى النتاجية

المنظمة.

ويمكن القول ان مستوى جودة حياة العمل تعد أحد المحفزات الأساسية التي تمكن الموظف من الاندماج في عمله، وحدد (Swamy, et. al., 2015, 288) المتغيرات الأساسية لجودة حياة العمل بالاتي: - التعويض المجزي والعادل: Adequate and fair compensation هي مستوى العائد الذي يساعد الموظف من تلبية التزاماته. فرص تطوير القدرات البشرية:Opportunity for developing using human capacity وهي لتهي التحسين والتدريب الذي توفره الحياة العملية للموظف. لتفرئ - التمسك بدستور المنظمة من خلال العمل: Constitutionalism هي الالتزام بالأساسيات والقوانين والقيم الوظيفية. ظروف عمل آمنة وصحية: Safe and healthy working conditions هي توفير بيئة عمل صحية وآمنه من خلال الوقاية من الحوادث والامراض وما تتفقه المنظمة على منعها او إعادة الموظف الى تلى فئه وضعه الطبيعي قبل حدوثها دلالة على الجودة في الحياة العملية. من جهة ثانية يقدم (Kanten and Sadullah, 2012, 362) المتغيرات الإجرائية للاندماج الوظيفي

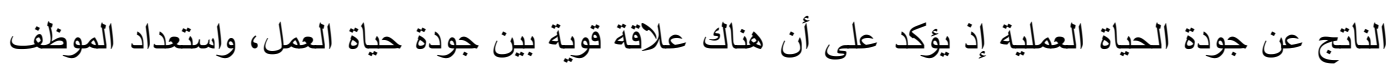

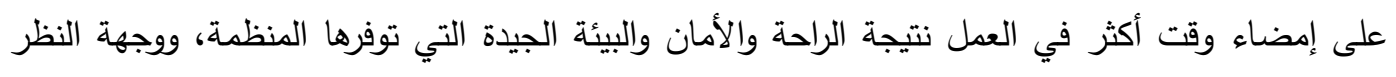

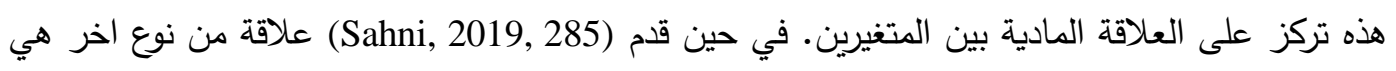
ان جودة الحياة العملية تقلل من ما يبذله الموظف في التواجد المكاني في العمل وذلك نابع من التطور والتقدم في تكنولوجيا المعلومات والأتمته التي تتيح للعمل من أن يؤدى بانسيابية دون الحاجة الى التواجد

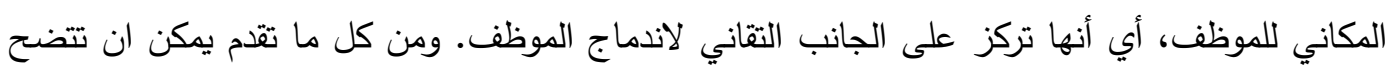


متغيرات الاندماج الوظيفي حسب ما قدمته (Rena, 2013, 10-11) في: أ) الاندماج الزمني

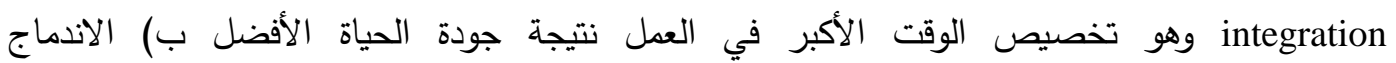
اللفظي(اللغوي) Verbal integration وهو التعلق بحياة العمل ونقلها الى الحياة الثخصية بكل ما تضمه من مصطلحات والفاظ ت) الاندماج المقترن بالأفعال Integration with actions هي الوظائف التي يؤديها الموظف في كل من الحياة الوظيفية والحياة الثخصية. وفي ضوء ما تقدم يمكن القول بأن أغلب الباحثين ركزوا على ان جودة حياة العمل ترتبط على نحو

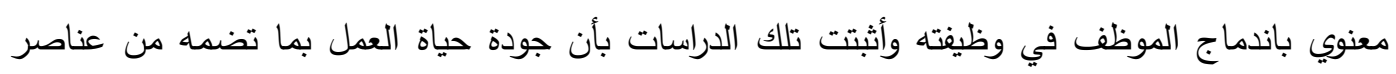
مادية ومعنوية تعمل على زيادة الراحة والرضا والأمان للموظف وبالتالتي زيادة اندماجه في عمله. ويوضح

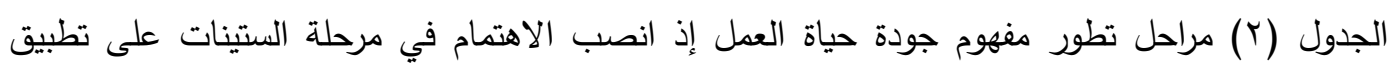

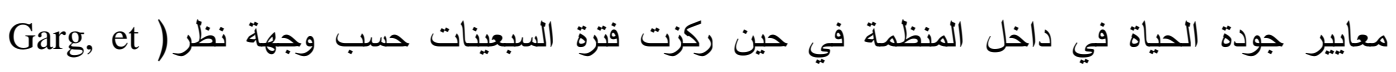

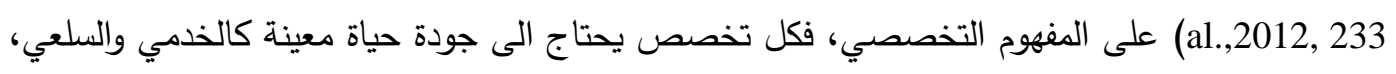
في حين انصب الاهتمام في فترة الثمانينات نحو البيئة المادية للمشروعات فقد أكد) (Daud, 2010, 77) على ضرورة توفير الإضاءة والتدفئة والمكان والمعدات كمتغيرات أساسية في بيئة جودة حياة العمل. وفي لهي فترة التسعينات أنصب الاهتمام على الجودة الوظيفية فاعتُبرت الوظيفة مقياساً لجودة الحياة فكانت المهارات والخبرات التي يتمتع بها الموظف وحسب وظائف المنظمة هي أساس جودة الحياة فظهرت جودة حياة رجال

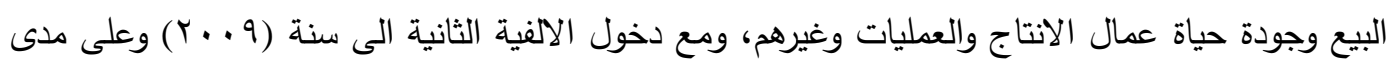

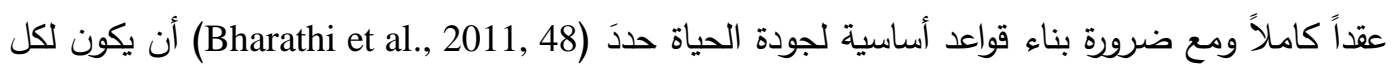
وظيفة قواعد أساسية لحياة العمل يفترض توافرها في الاتتاج سواء كان سلعياً أو خدمياً، وتطور هذا المفهوم

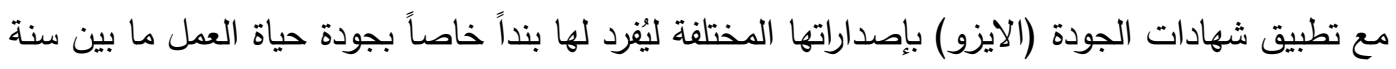

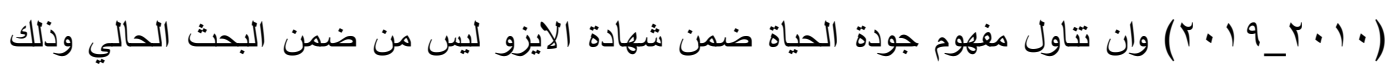

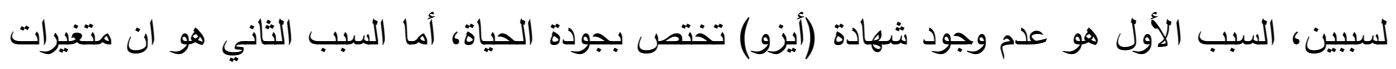
جودة الحياة عامة تختلف وفقاً لعدة أسس منها حسب نوع الانتاج وحسب أسلوب الإدارة وحسب متغيرات

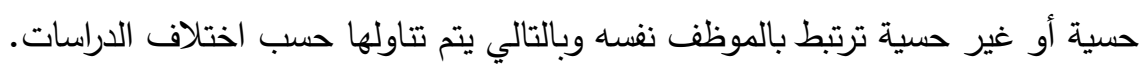

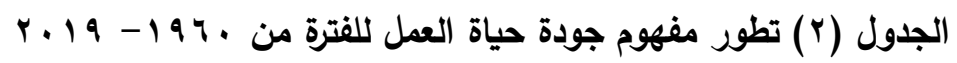

\begin{tabular}{|c|c|c|c|c|c|c|}
\hline $\begin{array}{l}-r \cdot 1 . \\
r+19\end{array}$ & $r_{\ldots} . q-r_{\ldots} \ldots$ & $\begin{array}{c}-199 . \\
1999\end{array}$ & $1919-191$. & $\begin{array}{l}-197 . \\
1989\end{array}$ & $1979-197$. & . \\
\hline عولمة جودة العمل & قواعد حياة العمل & الوظيفة & للمشروعات البيئة المادية & التخصصي & داخل المنظمة & $\overline{7}_{i=0}$ \\
\hline
\end{tabular}

المصدر: اعداد الباحشين 
من جهة اخرى إن اندماج العاملين في العمل يمكن أن يكون مؤشر لجودة الحياة العملية التي يعيشونها بغض النظر عن نوعية تلك الحياة سواء كانت جيدة او رديئة. ويوضح الثكل (Y) (Y) أهم مراحل

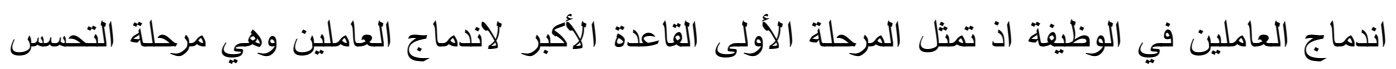

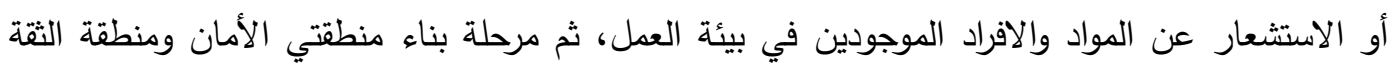
التي يحاول الموظف بنائهما ليمثلا الأمان في حياته الوظيفية، في حين ان المراحل الأخرى فتئن التسلسل

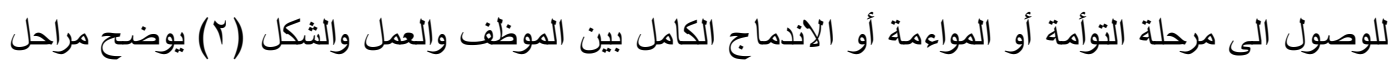
الاندماج الناتجة عن جودة الحياة.

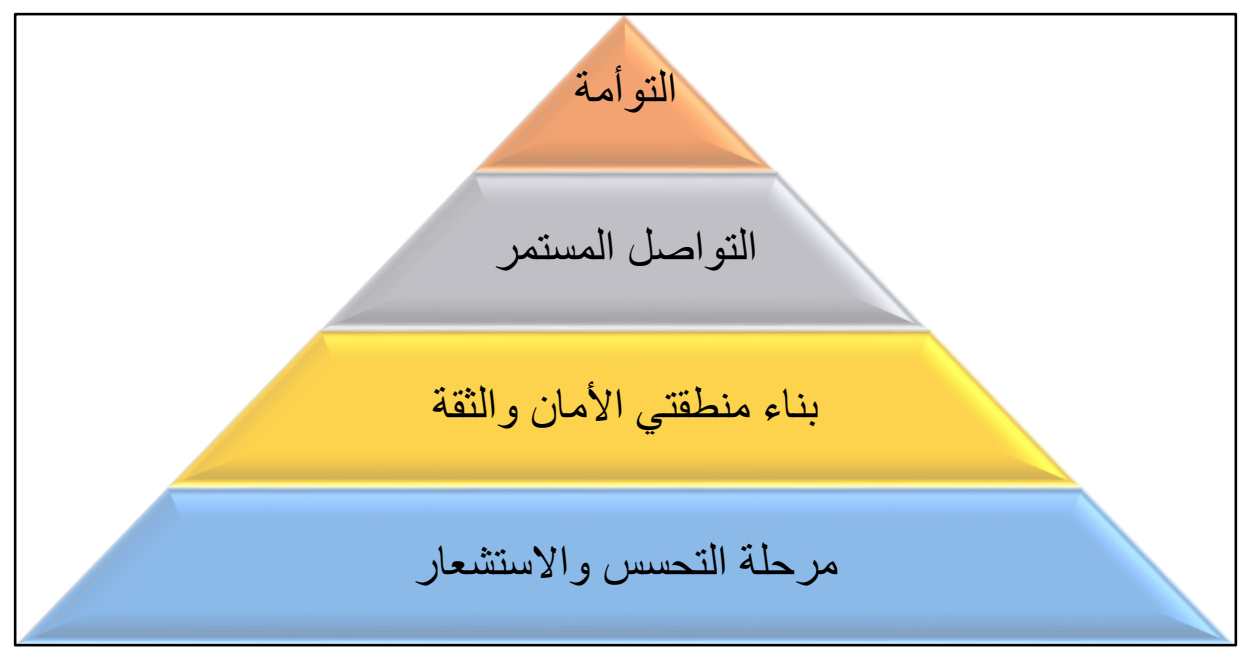

الثكل (ץ) مراحل اندماج العاملين نتيجة جودة حياة العمل المصدر: اعداد الباحثين r- تحليل واختبار فرضيات البحث

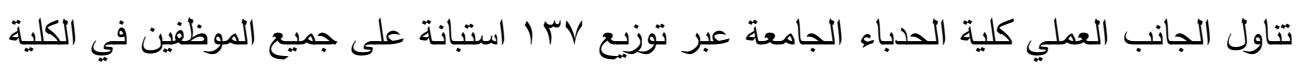
من المستويات الإدارية كافة وتم صياغة الأسئلة في الاستبانة على نحو يُمكن من اختبار انموذج البحث

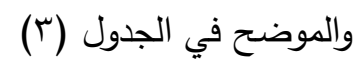
الجدول (r) توزيع فقرات الاستبانة على متغيرات البحث

\begin{tabular}{|c|c|c|c|}
\hline الرمز X & عدد المتغيرات & العناصر & المتغيرات \\
\hline $\begin{array}{c}1-5 \\
6-10 \\
11-15 \\
16-20\end{array}$ & 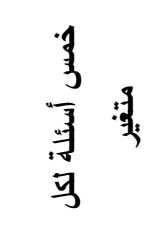 & التعويض المجزي & جودة حياة العمل QWL \\
\hline
\end{tabular}




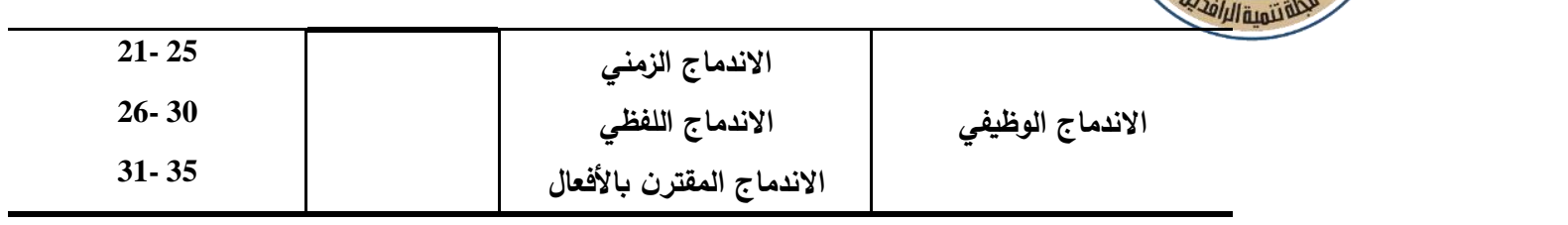

المصدر: اعداد الباحثين

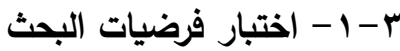

قدم البحث الحالي اثتتي عشر فرضية وسيتم اختبار مدى تحققها، وكذلك الإشارة الى أهم النتائج

$$
\text { المرتبطة بعنوان البحث الحالي وعلى النحو الاتي: }
$$

يوضح الجدول (ع) التباين في قيم اختبار الفرضيات التي قدمها البحث اذ جاءت في الغالبية العظمى منها قيم معنوية دلالة على تحقق التأثير العام لمتغيرات جودة حياة العمل في اندماج العاملين بأشكاله المختلفة، فمن حيث أثر متغيرات جودة الحياة في المتغير الأول الاندماج الزمني (الذي هو اني

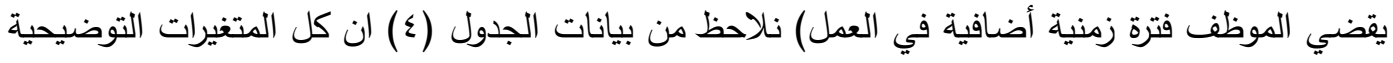
كانت ذات أثر معنوي في الاندماج الزمني فيما عدا دستور المنظمة اذ نلاحظ ان قيمة t المحسوبة بلغت 0.439 وهي اقل من مثيلتها الجدولية وان مستوى المعنوية لأنموذج تأثير دستور المنظمة في الأني الاندماج

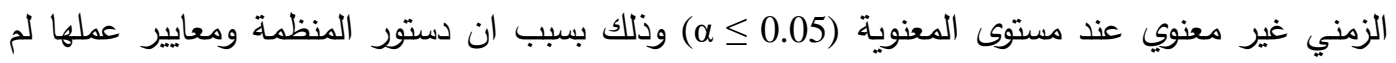
تمكن الفرد من ان يندمج في العمل خارج أوقات الدوام الرسمي وبالتالي لا يحقق الاندماج في ممارسة حياته الثخصية.

وفي حساب الأثر الأكبر لمتغيرات جودة حياة العمل QWL شَكل (التعويض الهزي) بدلالة قيمة Beta

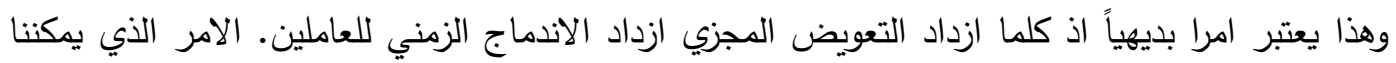

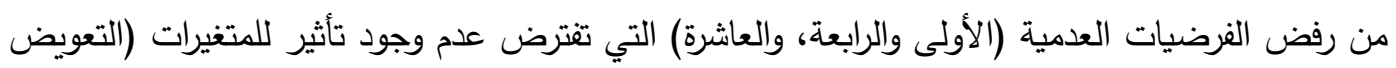

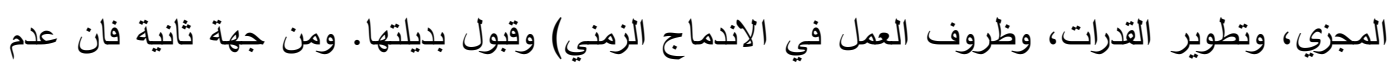

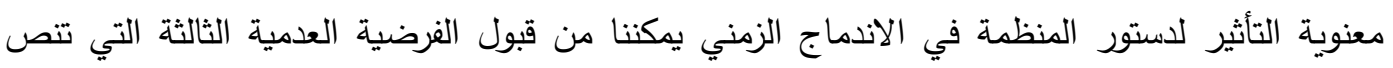

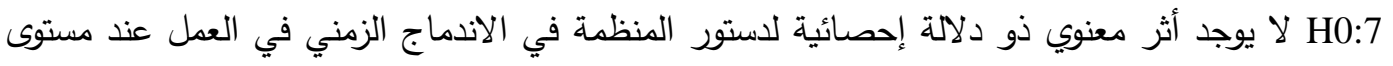

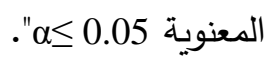

وفي حساب تأثير نفس المتغيرات التوضيحية لجودة الحياة من حيث (التعويض المجزي، وتطوير القدرات، ودستور المنظمة، وظروف العمل) في المتغير المعتمد (الاندماج اللفظي). نلاحظ من الجدول

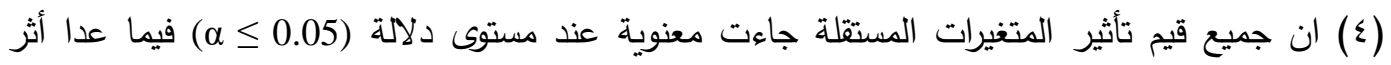
ظروف العمل في الاندماج اللفظي(اللغوي) جاءت غير معنوية وذلك بسبب اتئ ان العاملين لا يستخدمون المصطلحات(الالفاظ) المرتبطة بظروف العمل في حياتهم الثخصية كون ظروف العمل لا تضم متغيرات 
وابعاد متعددة تؤثر معنويا في حياتهم وشخصيتهم. كما ان الأثر الأكبر في هذا الانموذج كان لمتغير

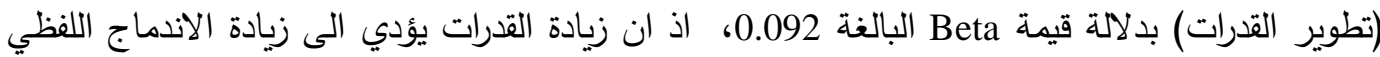
لاى الموظف وهذا يشكل سابقة للبحث الحالي اذ كلما ازداد استخدام مصطلحات(الفاظ) العمل بصورة متكررة أدى الى استخدامها في الحياة الثخصية للموظفين. الامر الذي يمكننا من رفض الفرضيات (الثانية، والخامسة، والثامنة) التي تفترض عدم وجود تأثير لكل من (التعويض المجزي، وتطوير القدرات،

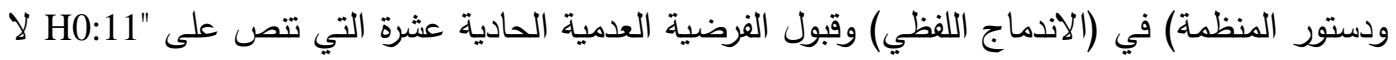
يوجد أثر معنوي ذو دلالة إحصائية لظروف العمل في الاندماج اللفظي عند مستوى المعنوية 0.05 ه

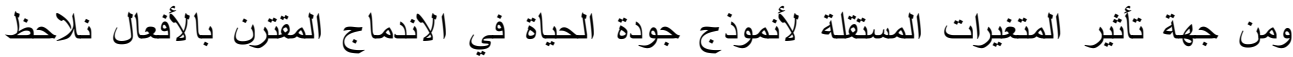
معنوية تأثير المتغيرات المستقلة (التعويض المجزي، تطوير القدرات، ودستور المنظمة) فقط في المتغير المعتمد (الاندماج المقترن بالأفعال) بمعنى كلما ازدادت التعويضات المجزية وازدادت البرامج التطويرية

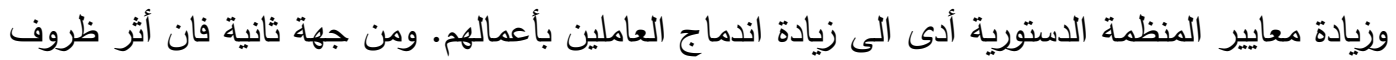
العمل في الاندماج المقترن بالأفعال جاء غير معنويا بمعنى ان ظروف العمل لا تؤثر في اندماج الموظف بأفعاله وهذه نتيجة منطقية إذ ان عدم منح الموظف التعويض المجزي وتطوير قدراته وتوفير معايير

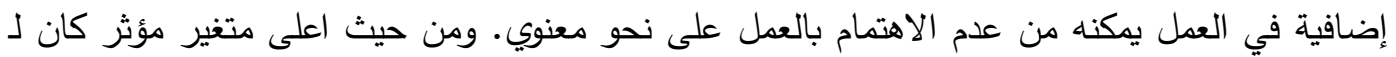
(ظروف العمل) في (الاندماج المقترن بالأفعال) بدلالة قيمة Beta بلغت 0.089 الامر الذي يؤكد ان الزيادة في توافر ظروف العمل سيؤدي الى اندماج العاملين في العمل عبر الاعمال التي يمارسونها في حياتهم

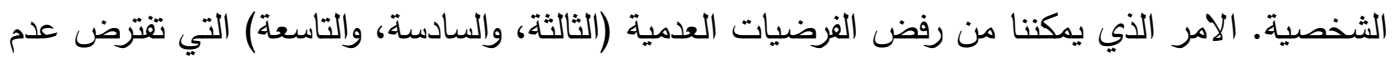
وجود تأثير لكل من (التعويض المجزي، وتطوير القدرات، ودستور المنظمة) في (الاندماج المقترن بالأفعال) وقبول الفرضية العدمية الثانية عشرة التي تتص على H0:12 لا يوجد أثر معنوي ذو دلالئل

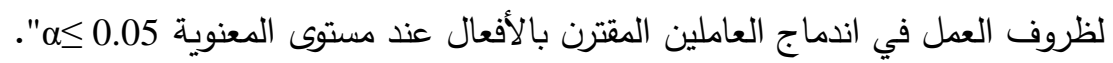
الجدول (؛) قيم اختبار الفرضيات لأنموذج اندار متغيرات جودة حياة العمل مجتمعة في أثكال اندماج العاملين كل على حدة

\begin{tabular}{|c|c|c|c|c|c|c|}
\hline المتغير المعتمد & اتجاه التاثير & المتغير المستقل & Beta & S.E. & CR & $\mathbf{P}$ \\
\hline \multirow{4}{*}{ الاندماج الزمني } & $<--$ & التعويض المجزي & .099 & .046 & 2.174 & .030 \\
\hline & $<---$ & تطوير القدرات & .094 & .059 & 1.579 & .014 \\
\hline & $<--$ & دستور المنظمة & -.023 & .052 & -.439 & .061 \\
\hline & $<--$ & ظروف العمل & .067 & .057 & 1.179 & .039 \\
\hline \multirow{2}{*}{ الاندماج اللفظي } & $<--$ & التعويض المجزي & -.016 & .019 & -.842 & .010 \\
\hline & $<--$ & تطوير القدرات & .092 & .047 & 1.974 & .048 \\
\hline
\end{tabular}


تأثير جودة حياة العمل (QWL) في الاندماج الوظيفي ..

سلطان والطائي

\begin{tabular}{|c|c|c|c|c|c|c|}
\hline المتغير المعتمد & اتجاه التاثير & المتغير المستقل & Beta & S.E. & CR & $\mathbf{P}$ \\
\hline & $<---$ & دستور المنظمة & .021 & .046 & .463 & .044 \\
\hline & $<--$ & ظروف العمل & .033 & .045 & .726 & .068 \\
\hline \multirow{4}{*}{ الاندماج المقترن بالأفعال } & $<---$ & التعويض المجزي & .034 & .026 & 1.299 & .034 \\
\hline & $<--$ & تطوير القدرات & .068 & .056 & 1.223 & .021 \\
\hline & $<--$ & دستور المنظمة & -.070 & .066 & -1.058 & .020 \\
\hline & $<--$ & ظروف العمل & .089 & .065 & 1.367 & .072 \\
\hline
\end{tabular}

المصدر: اعداد الباحثين بالاعتماد على مخرجات برنامج AMOS

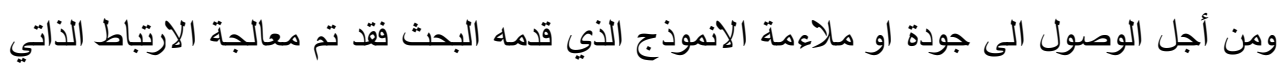

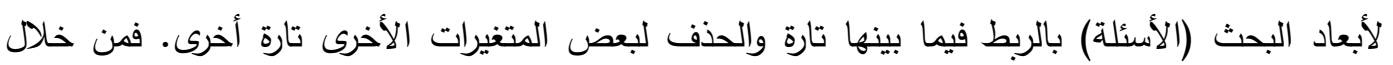

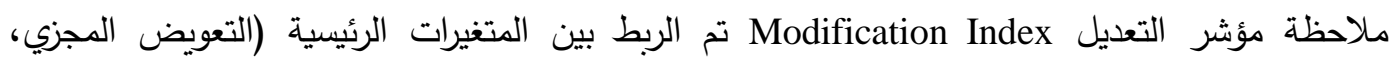

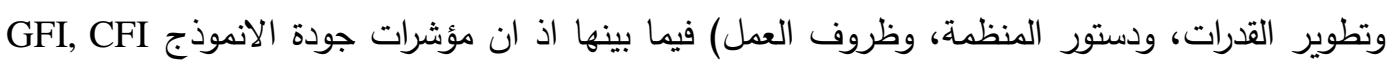
بلغا 0.77, 0.82 على التوالي وتم التتفيذ وارتفعت قيم الجودة ارتفاع طفيف ثم تم الربط والحذف على النحو الاتي:

- عمليات ربط الابعاد فيما بينها: تم الربط بين الابعاد (الأسئلة) حسب الجدول(0) إذ بعد كل عملية

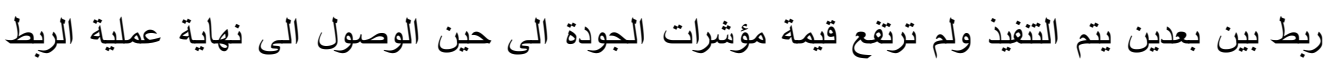

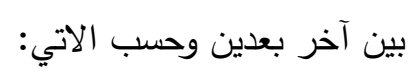

\section{الجدول (0) الأبعاد (الأسئلة) المترابطة فيما بينها لرفع جودة الانموذج}

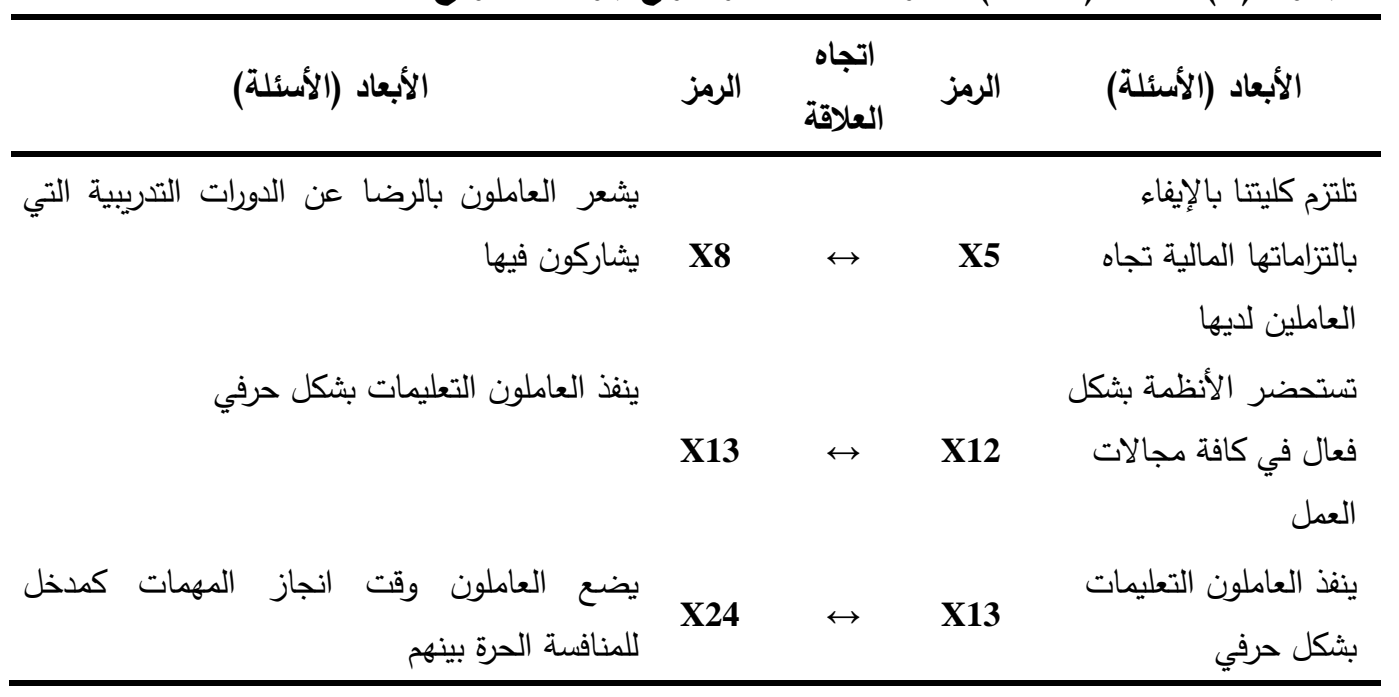




\begin{tabular}{|c|c|c|c|c|}
\hline تتميز بيئة الكلية بالنظافة والترتيب & X17 & $\leftrightarrow$ & $\mathrm{X} 16$ & توجد في الكلية بيئة عمل \\
\hline يوظف العاملون الدبلوماسية عند التعامل فيما بينهح & X26 & $\leftrightarrow$ & X27 & ديمرصة التقاعل وبروح ودية على \\
\hline
\end{tabular}

المصدر: اعداد الباحثين بالاعتماد على مخرجات برنامج AMOS

- حذف الابعاد: من أجل رفع قيم جودة انموذج البحث المقترح في البحث الحالي تم حذف الابعاد

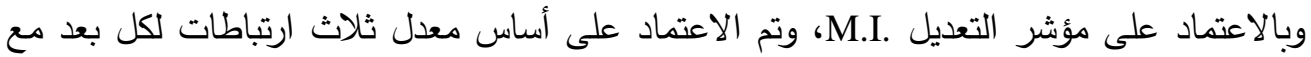
غيره من الابعاد فكل بعد يزيد ارتباطه عن ثلاث علاقات يتم حذفه كونه غير منطقي والموضحة في

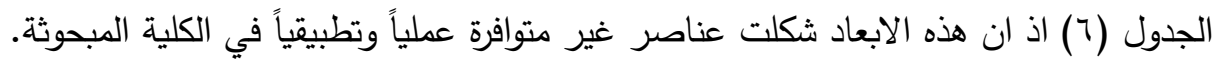

\begin{tabular}{|c|c|}
\hline 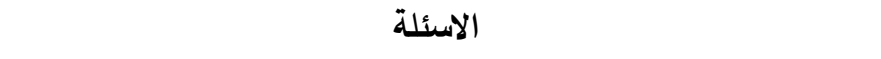 & 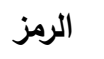 \\
\hline يترجم العاملون تحركاتهم الى واقع فعلي لأداء المهمات المناطة بهم & $\mathrm{X} 34$ \\
\hline تهيء الكلية العوامل النفسية الداعمة للأداء & $\mathrm{X} 18$ \\
\hline يتم توظيف المهارات السلوكية لتنظيم العلاقات بين العاملين & $\mathrm{X} 30$ \\
\hline تشجع الكلية العاملين على وضع الخطط المستقبلية لتطوير وضعهم & $\mathrm{X} 7$ \\
\hline
\end{tabular}

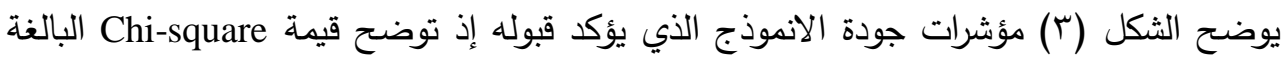

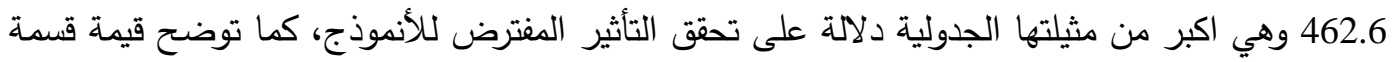
Chi-square من 0.05 حسب افتراض (Arbuckle, et. al., 2013, 943-950). في حين بينت قيمة كل من جودة الانموذج وجودة المقارنة من ما معدله CFI and GFI 0.94 and وهو اكبر من الحد المعياري البالغ 0.90 دلالة على المقبولية المناسبة للأنموذج ليمثل خوارزمية العلاقة المفترضة لأنموذج أثر جودة حئه العمل في اندماج العاملين. كما تتوافر مؤشرات تدل على ملائمة الانموذج منها انموذج الملائمة المصحح 
الذي بلغ 0.89 دلالة على جودته كونه قريب من الواحد الصحيح الا انه اقل من 0.90. والمؤشر

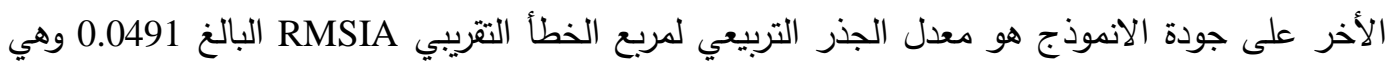
اقل من 0.05 حسب افتراض(Hire et. al., 2010,10) دلالة على مقبولية الانموذج وقلة الانحراف البيني فلي فيما بين الإجابات على الاستبانة.

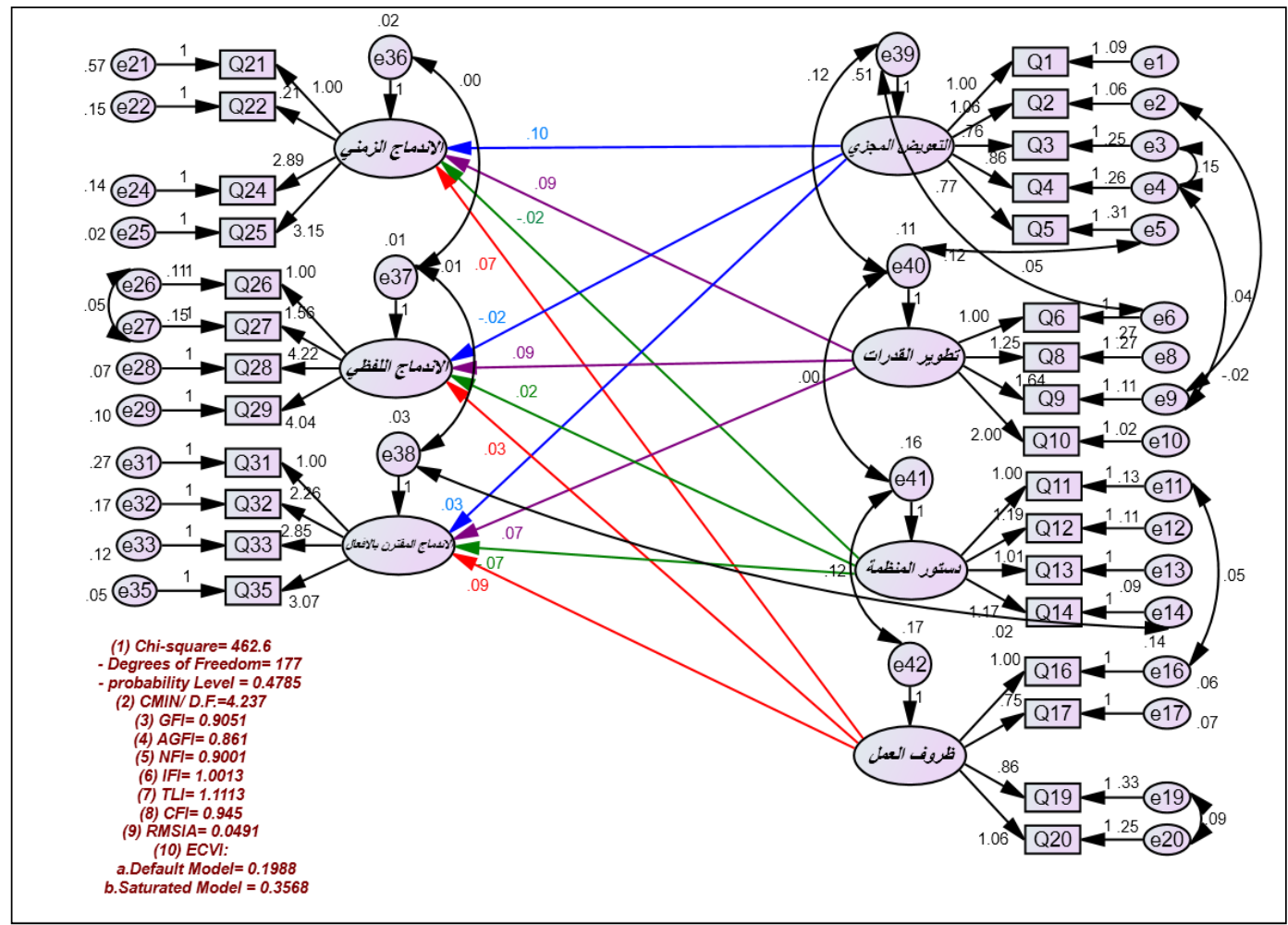

AMOS الثكل (r) اختبار مخطط البحث الافتراضي وفق انموذج المعادلات البنائية المصدر: اعداد الباحثين بالاعتماد على مخرجات برنامج AMOS

الاستنتاجات

ا. ـ أشارت نتائج البحث بوجود تأثير ذو دلالة معنوية لجودة حياة العمل بمتغيراتها المختلفة من جهة على الاندماج الوظيفي بمتغيراته المختلفة من جهة أخرى لدى العاملين في الكلية المبحوثة.

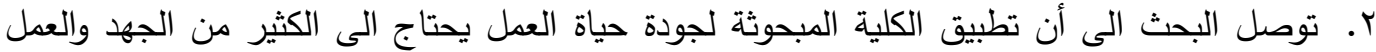
كي يندرج هذا المنهج الإداري الحديث ضمن الأولويات في هذه الكلية، والتي أخذت معظم المنظمات والإدارات الحديثة بتطبيقه، كون هذا المنهج يعمل على دعم وبناء هذه المنظمات بكافة أنواعها 
وتبعياتها. كما تثير نتائج البحث ان مستوى الاندماج الوظيفي لدى العاملين في الكلية المبحوثة كانت

بدرجة متوسطة.

r. كما بَينت نتائج البحث ان بيئة العمل لها أهمية كبيرة كمقياس لجودة حياة العمل، من خلال توفير ظروف عمل صحية وآمنة، بمعنى ان مشاركة إدارة المنظمة في توفير بيئة عمل متميزة تعطي مدلول للفرد العامل بأن المنظمة التي يعمل بها تهتم بجودة حياته المهنية، الأمر الذي سينعكس على النيل اندماجه ء. . يوجد نظام واضح للتعويضات المالية داخل الكلية المبحوثة لكن بنسب منخفضة، وذلك لان العديد من

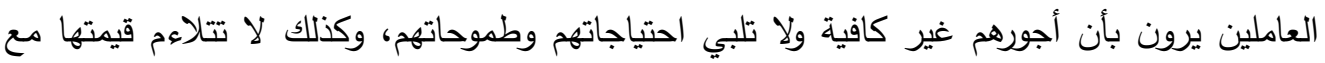
حجم ونوع العمل الذي يقومون به، وان هذه الأجور غير عادلة مقارنة بما يتقاضاه العاملين بنفس

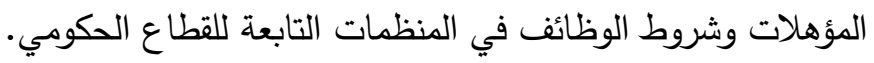
ه. هاك حالة من الايجابية بشأن تقاسم المهات بين الموظفين في ميدان العمل، وحسب ما أفصدت عنه إجابات المبحوثين في الكلية المبحوثة، وعلى نحو يضفي قدراً من المشاركة في توزيع المهمات.

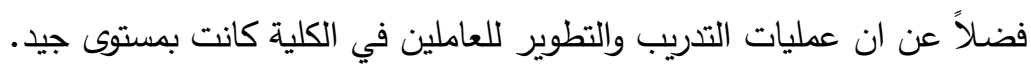

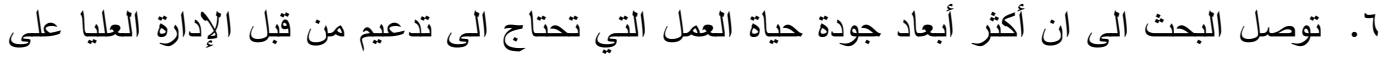
الترتيب هي الأبعاد المرتبطة بالجوانب المالية والاقتصادية يليها الأبعاد المرتبطة بعوامل بيئة وظروف الئل

العمل ويليها الأبعاد المرتبطة بالجوانب التتظيمية والوظيفية. التوصيات

ا. ضرورة عقد دورات وورش عمل متقدمة للعاملين في الكلية المبحوثة تتعلق بطبيعة وجدوى تطبيق

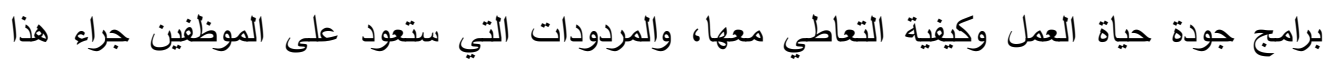
التطبيق. r. التأكيد على دور الإدارة العليا في بناء علاقات طيبة بين العاملين يسودها جو من التقة المتبادلة،

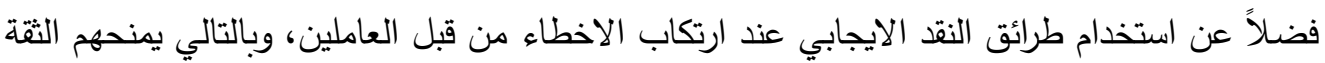
بأنفهر ويزيد من اقبالهم على العمل. r. ضرورة أن تولي الكلية المبحوثة الاهتمام بتوفير ظروف وبيئة عمل صحية وآمنة، تعمل على تلبية

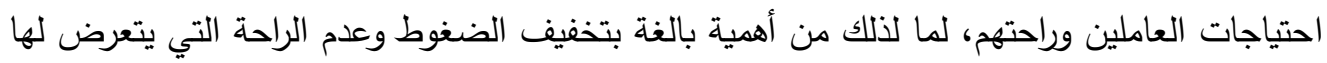
العاملين وبالتالي زيادة اندماجهم في العمل. ء. ضرورة إعادة النظر بنظام التعويضات المالية المطبق حالياً في الكلية المبحوثة، بما يتلاءم مع لعادئ احتياجات العاملين ومتطلبات العيش الكريم لهم ولأسرهم. 
0. الاهتمام بتحقيق الاندماج الوظيفي للعاملين بواسطة برامج مدروسة، فضلاً عن منح العاملين

صلاحيات كافية تتلاءم مع قدراتهم ومؤهلاتهم فهذا يجعل العامل يُشعر بأنه مهم في عمله وله دور بله

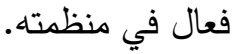

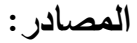

1- Al-Haddad, Nermin Salman, 2018, The Role of Employee Inclusion in Raising Their Performance in Private Syrian Banks, Unpublished Master Thesis, Syrian Virtual University, Syria.

2- Zahir, Tayseer, 2016, The Impact of Quality of Work Life on Organizational Commitment: "A field study on the Citizen Service Center in Damascus Governorate, Tishreen University Journal for Research and Scientific Studies, Volume 38, Issue 1, Syria.

3- Morsi, Mervat Muhammad Al-Saeed, 2013, The Impact of Talent Management on the Integration of Employees through the Balance between Work and Family as a Mediating Variable, "A Field Study on Zagazig University Hospitals", Jordanian Journal of Business Administration, Leather 9, Issue 1.

4- Arbuckle, J. L., 2010, IBM SPSS Amos ${ }^{\mathrm{TM}} 19$ User's Guide, Crawfordville, FL: Amos Development Corporation, Chicago, USA.

5- Bharathi, P., Kumar, N., \& Umaselvi, M., 2011, "Quality Of Work Life: Perception Of College Teachers", Indian Journal of Commerce \& Management Studies, Vol. (11), No. (1).

6- Daud, N., 2010, Investigating the Relationship Between Quality of Work Life and Organizational Commitment Amongst Employees in Malaysian Firms, International Journal of Business and Management, Vol. (05), No. (10).

7- Daud, N., 2012, the Influence of quality of work life on organizational commitment: A study on Academic staff in public Institution of Higher learning in Malaysia, international conference on Innovation, management and technology research(ICIMTR), Malacca, Malaysia.

8- Easton, S., Van Laar, D., 2018, User manual For the work Related Quality of Life (WRQOL) Scale: a measure of quality of Working Life, university of Portsmouth .

9- Garg, C. P., 2012, Quality of work life: An Overview, international Journal of Physical and Social Sciences, Vol. (2), No. (4).

10- Hair, J. F. \& Blak W. C.\& Babin B. J. \& Anderson, R. E. \& Tatham, R. L., 2010, Multivariate Data Analysis, 7th ed., New York, Unaided States of America.

11- Kanten, S., and Sadullah, O.,2012, An empirical research on relationship quality of work life and work engagement, Procedia-Social and Behavioral Sciences, No. (62), 360-366.

12- Kasaya, M. A., and Munjuri, M. G., 2018, Effect of Employee Involvement on Job Performance in the Medical Research Industry in Kenya, International Journal of Economics, Commerce and Management, Vol. (6), No. (5), 826-847.

13- Leitao, J., Pereira, D., and Gonçalves, A., 2019, Quality of Work Life and Organizational Performance: Workers' Feelings of Contributing or Not to the 
Organization's Productivity, International journal of environmental research and public health, Vol. (16), No. (20), 3803.

14- Mukherjee, S. P., 2019, quality: Domains and Dimensions, Springer Nature Singapore pte Ltd.

15- Rena, D.Y., 2013, A case study of employee engagement in AkzoNobel Corporate HR, Master's thesis, University of Twente.

16- Sahni, J., 2019, Role of Quality of work life in determining employee engagement and organizational commitment in telecom industry, International Journal for Quality Research,Vol. (13), No. (2).

17- Swamy, D.R ., Nanjundewaraswamy, T . S ., andRashmi, S ., 2015, Quality Of work Life : Scale development and validation, International Journal of Caring Sciences , Vol. (8), No. (2). 